\title{
3D Scanning: Conference Documentation
}

\author{
Denise Allan \\ Edinburgh Napier University \\ 10 Colinton Road, Edinburgh \\ denise.allan@napier.ac.uk
}

\begin{abstract}
"I'm going to give you each a little bit of plasticine and I want you to play with it while I talk. I want you to make a model; it can be anything you like. Don't be self-conscious, just go for it. Play with it, have fun, pretend you're 5 again."
\end{abstract}

This is how the Allan starts all of her conference presentations. Throughout her PhD journey she intends to use this as a way of documenting conferences and perhaps capturing data about what people want to make, or at least what they say they want to make when they're forced to think of something on the spot.

3D printing, 3D scanning, Conferences, Documentation

\section{INTRODUCTION}

The intention of the installation, 'Make What You Desire' is to make the user feel liberated from manufacturing constraints. They are invited to use plasticine to model anything they like. This is then 3D scanned and 3D printed to form part of a larger visual archive of what people would 3D print if they could print anything. Users will be able to access this visual archive online and download their scan which can be 3D printed wherever they have access to a 3D printer. The scanner is a little different from conventional scanners though. It was developed from an open source project by the author, to improve the scan quality of small objects.

Conventionally 3D scanners struggle to pick up small details. This scanner is still a work in progress but has been used at several conferences as a new way of conference documentation. The scanner does not always see what is expected and therefore creates some interesting interpretations of users models.

\section{EXISTING METHODS FOR EXPERIENCE DOCUMENTATION}

The documentation of experiences across disciplines is currently a topic of interest. In education and teaching, Suarez (2017) discusses the benefits of documentation of pedagogical approaches and teachers experiences in aiding the their own understanding and memory of the subject. He suggests that by having to consider their roles as teachers by reading, writing and observing they engage in an iterative process which gives more meaning to how the view themselves and what they teach.

In medicine, Vestala (2013) researched how patients' participation in the documentation of their own medical conditions and progress can influence their involvement in the decisions regarding their care. The data suggested that when patients were involved in the documentation they sought more information and a clearer understanding, which therefore led to those patients being more involved in their care decisions.

In terms of media art, Jones (2008) discusses how documentation generally considers the physical composition of the art as well as the artist's intention. However, she highlights that it is important to document how the artwork occurs for the viewer, as it is this experience that makes the art exist for an audience in the real world.

When considering these few examples, it is clear that participation in documentation can be beneficial and improve overall experience for everyone involved. 


\section{CONFERENCE DOCUMENTATION}

Make what you desire encourages delegates to contribute to the documentation of conferences. It can provide unique and interesting insights into how the delegates experience the conference as well as improve their own experience of the conference by participating in a making process, which in itself has been shown to be beneficial to wellbeing. (Anderson, 2012)

\section{MAKE WHAT YOU DESIRE}

So far the 3D scanner as part of this exhibition has been exhibited at Edinburgh Mini Maker Faire, at the Research Through Design Conference as well as part of the interactions gallery at the $\mathrm{BHCl} 2017$.

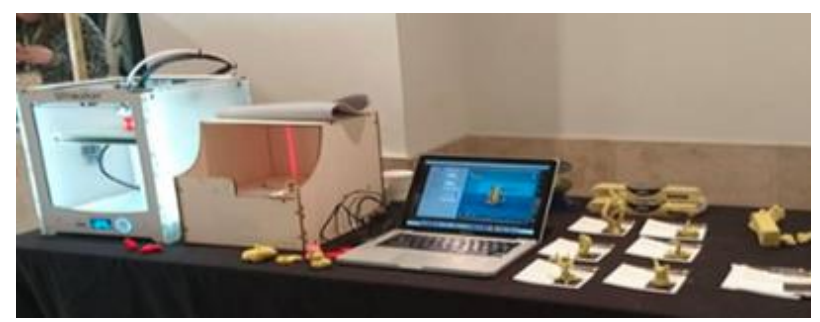

\section{Figure 1}

Figure 1 shows the set up of the scanner at the Research Through Design conference at the National Museum of Scotland. (L-R 3D printer, 3D scanner, laptop, models made by delegates). During the conference, as many models were printed as possible. It takes as little as 30 minutes to turn the lump of plasticine into a 3D printed model.

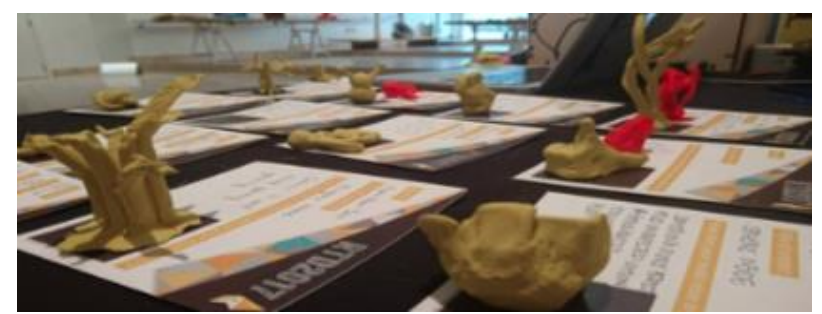

\section{Figure 2}

Figure 2 illustrates a close up of plasticine models made by delegates. They were asked to make an object based on their experience or something they learned at the conference. These models included a tree which the maker sat next to a piece of text which explained that it represented the many research fields that are coming out of design. This highlights the role that this type of documentation may have in also helping delegates note how they feel or what they think of a particular topic that they may feel self-conscious to write as a stand-alone piece.

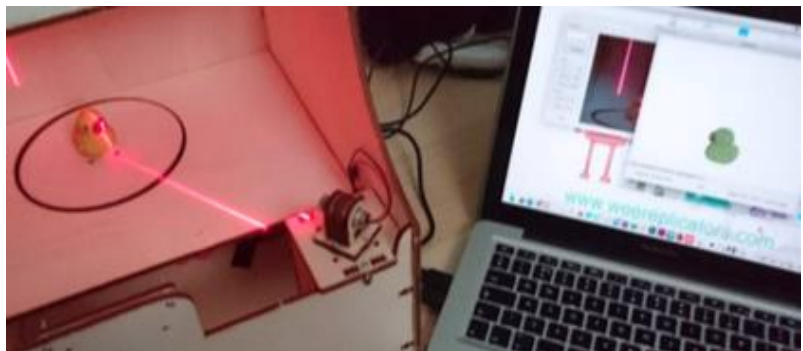

Figure 3

The interior of 3D scanner can be seen in figure 3 . It was made using an Arduino board, a motor, a laser pen and an old webcam housed in a laser cut box. The aim was to make it as accessible as possible. Anyone can make one for approximately $£ 40$, though the results are unpredictable so it is certainly far from ready for commercialization though for a hobbyist or enthusiast it would be an interesting project.

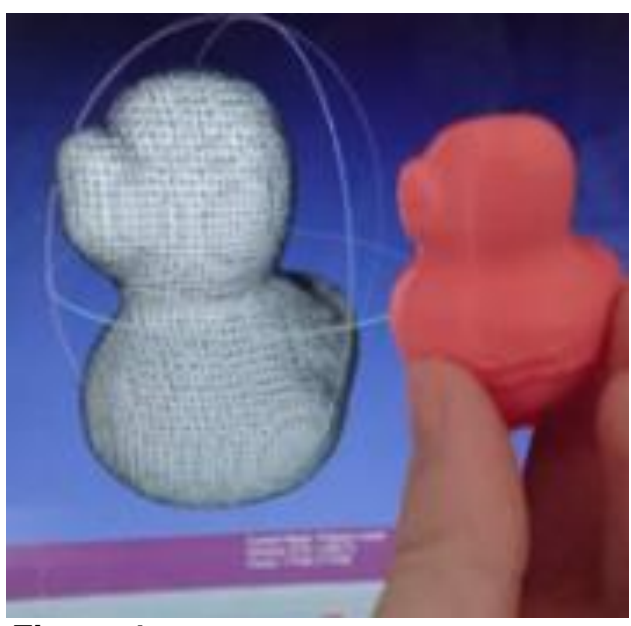

Figure 4

The scan, mesh and 3D print of the scan is illustrated in figure 4. Meshlab is used to convert the point cloud into an STL. file ready for slicing on a 3D printer. This is all demonstrated to the interested delegates so they can understand the process taken to digitize their plasticine model, which improves overall delegate satisfaction.
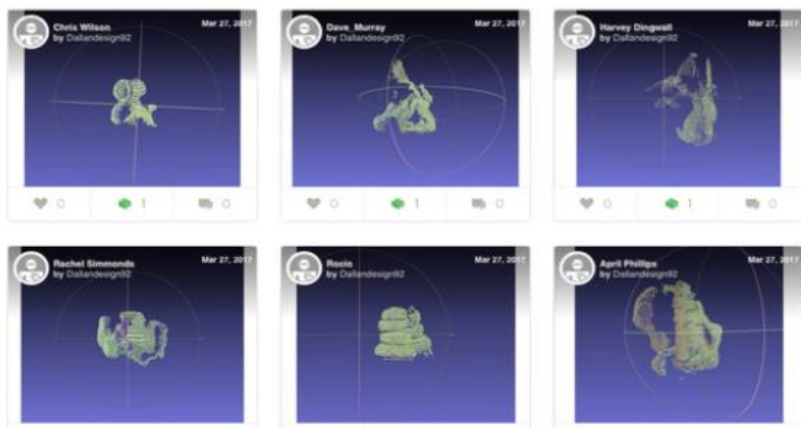


\section{Figure 5}

The visual collection can be viewed and downloaded on Thingiverse at the following web address, (https://www.thingiverse.com/Dallandesign 92/collections/rtd2017) this takes the conference beyond the designated days and can help what was learned and the connections made at the conference longer lasting and more meaningful.

\section{CONCLUSION}

'Make What You Desire' is a project, which forms part of the author's PhD research. Her research surrounds the idea of digital making and how it can be used to increase social capital. One of the issues in getting digital making tools into schools is that it has, to an extent, become branded as gimmicky and not the ground breaking technology that was promised. Therefore, to justify this integration into schools Allan is trying to find out what people want to print. While, at the same time introducing as many people to the technology as possible to foster a familiarity with it, so that when more schools and community spaces do get 3D printers people already know how they work and want to use them. Additionally, 3D printing offers the unique opportunity to create things, which were never possible before, such as complex internal structures and undercuts. As designers, engineers and makers our imaginations are somewhat limited by what we know is possible. 'Make What You Desire' provides a tool for playful interactions to challenge what is really possible.

\section{REFERENCES}

Anderson, C. (2013) Makers : the new industrial revolution, London: London : Random House Business Books.

Jones, C. and Muller, L. (2008) 'Between Real and Ideal: Documenting Media Art', Leonardo, 41(4), 418-419.

Suarez, D. H. (2017) 'The Narrative Documentation of Pedagogical Experiences and the Democratization of Professional Development and Schooling in Argentina', International Journal of Qualitative Studies in Education (QSE), 30(5), 474-487.

Vestala, H. and Frisman, G. H. (2013) 'Can participation in documentation influence experiences of involvement in care decisionmaking?', The open nursing journal, 7, 66 .

\section{AUTHOR BIOGRPAHY}

Denise Allan is a $\mathrm{PhD}$ candidate at Edinburgh Napier University. Her research is focused on design and making in education contexts and how it can impact on social capital. She runs a business and social enterprise, which provides 3D printing education in Scotland through schools, youth organisations and charities. 